Check for updates

Cite this: RSC Adv., 2018, 8, 2963

\title{
Improvement of $\mathrm{O}_{2}$ adsorption for $\alpha-\mathrm{MnO}_{2}$ as an oxygen reduction catalyst by $\mathrm{Zr}^{4+}$ doping
}

\begin{abstract}
Yicheng Wang, (D) ${ }^{a}$ Yaozong Li, ${ }^{a}$ Zhenghang $\mathrm{Lu}^{\mathrm{b}}$ and Wei Wang ${ }^{\star a}$
$\mathrm{Zr}^{4+}$ doped $\alpha-\mathrm{MnO}_{2}$ nanowires were successfully synthesized by a hydrothermal method. XRD, SEM, TEM and XPS analyses indicated that $\mathrm{Mn}^{3+}$ ions, $\mathrm{Mn}^{4+}$ ions, $\mathrm{Mn}^{4+\delta}$ ions and $\mathrm{Zr}^{4+}$ ions co-existed in the crystal structure of synthesized $\mathrm{Zr}^{4+}$ doped $\alpha-\mathrm{MnO}_{2}$ nanowires. $\mathrm{Zr}^{4+}$ ions occupied the positions originally belonging to elemental manganese in the crystal structure and resulted in a mutual action between $\mathrm{Zr}^{4+}$ ions and $\mathrm{Mn}^{3+}$ ions. The mutual action made $\mathrm{Mn}^{3+}$ ions tend to lose their electrons and $\mathrm{Zr}^{4+}$ ions tend to get electrons. Cathodic polarization analyses showed that the electrocatalytic activity of $\alpha-\mathrm{MnO}_{2}$ for oxygen reduction reaction (ORR) was remarkably improved by $\mathrm{Zr}^{4+}$ doping and the $\mathrm{Zr} / \mathrm{Mn}$ molar ratio notably affected the ORR performance of the air electrodes prepared by $\mathrm{Zr}^{4+}$ doped $\alpha-\mathrm{MnO}_{2}$ nanowires. The highest ORR current density of the air electrodes prepared by $\mathrm{Zr}^{4+}$ doped $\alpha-\mathrm{MnO}_{2}$ nanowires in alkaline solution appeared at $\mathrm{Zr} / \mathrm{Mn}$ molar ratio of $1: 110$, which was $23 \%$ higher than those prepared by $\alpha-\mathrm{MnO}_{2}$ nanowires. EIS analyses indicated that the adsorption process of $\mathrm{O}_{2}$ molecules on the surface of the air electrodes prepared by $\mathrm{Zr}^{4+}$ doped $\alpha-\mathrm{MnO}_{2}$ nanowires was the rate-controlling step for ORR. The DFT calculations revealed that the mutual action between $\mathrm{Zr}^{4+}$ and $\mathrm{Mn}^{3+}$ in $\mathrm{Zr}^{4+}$ doped $\alpha-\mathrm{MnO}_{2}$ nanowires enhanced the adsorption process of $\mathrm{O}_{2}$ molecules.
\end{abstract}

Received 10th September 2017
Accepted 23rd December 2017

DOI: $10.1039 / \mathrm{c} 7 \mathrm{ra10079e}$

rsc.li/rsc-advances crystallographic structure, following an order of $\alpha>\beta>\gamma$ as reported in the literature. ${ }^{28}$ The structural variations of manganese dioxides result from the different bonding ways of the basic $\left[\mathrm{MnO}_{6}\right]$ octahedral units. Among them, $\alpha-\mathrm{MnO}_{2}$ possesses both $(2 \times 2)$ and $(1 \times 1)$ tunnels surrounded by double binding octahedral chains, $\beta-\mathrm{MnO}_{2}$ consists of only $(1 \times 1)$ tunnels separated by single chains, and $\gamma-\mathrm{MnO}_{2}$ displays $(1 \times 1)$ and $(1 \times 2)$ tunnels enveloped in double chains. ${ }^{29}$ To the best of our knowledge, morphology is another important influential factor for the electrochemical properties. It was reported that $\alpha-\mathrm{MnO}_{2}$ nanowires possess enhanced electrocatalytic activity compared to the other two shapes namely nanotubes and nanoparticles despite the nanotubes showing a much higher specific surface area. $^{30}$

Previous research on manganese dioxide as the catalysts toward the ORR mainly focused on the effect of the morphology, crystallographic structure and chemical composition on the catalytic activity. ${ }^{31-34}$ Recently, most research has been concentrated on further improving the ORR activity by hybridizing or doping manganese oxides with other transition metals, such as $\mathrm{Ag}{ }^{35-37} \mathrm{Pd}^{38}$ and Ni. ${ }^{39,40} \mathrm{Zr}^{4+}$ doped cathode materials for metalion batteries could improve electronic structure and electrochemical performance. ${ }^{\mathbf{4 1 , 4 2}} \mathrm{Up}$ to now, related studies on $\mathrm{Zr}^{4+}$ doped $\alpha-\mathrm{MnO}_{2}$ have not been reported yet.

In the present work, $\mathrm{Zr}^{4+}$ doped $\alpha-\mathrm{MnO}_{2}$ nanowires were prepared via an in situ hydrothermal method. The structures and properties were characterized using X-ray diffraction (XRD), scanning electron microscopy (SEM), transmission electron
${ }^{a}$ Department of Applied Chemistry, School of Chemical Engineering and Technology, Tianjin University, Tianjin 300072, PR China. E-mail: wangweipaper@163.com; Fax: +86-22-27403389; Tel: +86-13512958953

${ }^{b}$ Kimball Union Academy, NH 03770, USA 
microscopy (TEM) and X-ray photoelectron spectroscopy (XPS). The electrocatalytic activity of $\mathrm{Zr}^{4+}$ doped $\alpha-\mathrm{MnO}_{2}$ nanowires for ORR was evaluated by cathodic polarization curve (CPC) and electrochemical impedance spectroscopy (EIS) measurements. The enhancement mechanism of $\mathrm{Zr}^{4+}$ doping was further explored by density functional theory (DFT) calculations.

\section{Experimental}

\subsection{Catalyst synthesis}

Manganese dioxide $\left(\alpha-\mathrm{MnO}_{2}\right)$ nanowires were synthesized via a hydrothermal method as reported in the literatures. ${ }^{43,44}$ Typically, $30 \mathrm{~mL}$ of $0.1 \mathrm{M} \mathrm{KMnO}_{4}$ aqueous solution was dropped into $30 \mathrm{~mL}$ of the $\mathrm{MnSO}_{4}$ solution $(0.1 \mathrm{M})$ at room temperature with vigorous stirring for $30 \mathrm{~min}$. Then the mixture was transferred into a $100 \mathrm{~mL}$ Teflon-lined autoclave reactor to perform a hydrothermal reaction at $140{ }^{\circ} \mathrm{C}$ for $24 \mathrm{~h}$ in a hot air oven. After that, the reactor was cooled naturally to room temperature. The obtained precipitate was washed several times with distilled water and ethanol. Finally, the product was dried overnight in an oven at $60{ }^{\circ} \mathrm{C}$ and used for further characterization.

For the synthesis of $\mathrm{Zr}^{4+}$ doped $\alpha-\mathrm{MnO}_{2}$ nanowire catalysts, a certain amount of $\mathrm{Zr}\left(\mathrm{NO}_{3}\right)_{4} \cdot 5 \mathrm{H}_{2} \mathrm{O}$ was added into $30 \mathrm{~mL}$ of $0.1 \mathrm{M} \mathrm{MnSO}_{4}$ solution under vigorous stirring until the formation of a homogeneous solution. The dosage of $\mathrm{Zr}\left(\mathrm{NO}_{3}\right)_{4} \cdot 5 \mathrm{H}_{2} \mathrm{O}$ changed depending on the $\mathrm{Zr} / \mathrm{Mn}$ molar ratio desired $1: 70$, $1: 90,1: 110,1: 140$ and $1: 150$. The other preparation processes were exactly the same with the preparation of $\alpha-\mathrm{MnO}_{2}$ nanowires.

\subsection{Physical characterization}

The X-ray diffraction (XRD) patterns of the prepared $\alpha-\mathrm{MnO}_{2}$ and $\mathrm{Zr}^{4+}$ doped $\alpha-\mathrm{MnO}_{2}$ catalysts were recorded with a Rigaku MiniFlex II X-ray diffractometer using $\mathrm{Cu} \mathrm{K} \alpha$ radiation with a $\mathrm{Ni}$ filter. The tube current was $30 \mathrm{~mA}$ with a tube voltage of $40 \mathrm{kV}$. The $2 \theta$ angular regions between $20^{\circ}$ and $75^{\circ}$ were explored at a scan rate of $4^{\circ} \mathrm{min}^{-1}$. The morphologies and surfaces of the prepared catalysts were investigated using a Nanosem 430 fieldemission scanning electron microscope (FE-SEM, FEI Company) with an acceleration voltage range of $10-30 \mathrm{kV}$ and a Philips Tecnai G2 F20 field-emission transmission electron microscope (TEM, FEI Company) operated at $200 \mathrm{kV}$. The binding energy of the elements in the catalysts was analyzed by X-ray photoelectron spectroscopy (XPS, PHI1600 ESCA System, PERKIN ELMER, USA) with Al K $\alpha$ radiation $(h v=1486.6 \mathrm{eV})$.

\subsection{Preparation of the air electrode}

Briefly, the air electrode was prepared by dispensing $2.2 \mathrm{~g}$ of the synthesized catalyst, $1.1 \mathrm{~g}$ of acetylene black and $2.1 \mathrm{~g}$ of polytetrafluoroethylene (PTFE, $60 \mathrm{wt} \%$ ) into $20 \mathrm{~mL}$ of ethanol. The mixture was stirred at room temperature for 1 hour and then stirred continually at $60{ }^{\circ} \mathrm{C}$ for 15 minutes until the mixture getting together. Afterwards, the mixture was rolled to form a film with thickness $0.6 \mathrm{~mm}$. Finally, the film was coated onto a stainless steel net with area $2 \mathrm{~cm} \times 2 \mathrm{~cm}$.

\subsection{Electrochemical measurements}

The electrochemical measurements were carried out in a threeelectrode and two-circuit electrochemical cell. One side of the working electrode was immersed in a $3 \mathrm{M} \mathrm{KOH}$ solution and the other side was exposed to the air. A ruthenium-titanium mesh was used as a counter electrode. $\mathrm{An} \mathrm{Hg} / \mathrm{HgO}(3 \mathrm{M} \mathrm{KOH})$ reference electrode was used through a salt bridge, and all the potentials in this work were referred to $\mathrm{Hg} / \mathrm{HgO}(3 \mathrm{M} \mathrm{KOH})$ reference electrode. The cathodic polarization curves were recorded from the open circuit potentials and the scan rate of the potential was $0.5 \mathrm{mV} \mathrm{s}^{-1}$. Electrochemical impedance spectroscopy (EIS) measurements were performed with an applied potential amplitude $\pm 5 \mathrm{mV}$ in a frequency range from $10 \mathrm{kHz}$ to $10 \mathrm{mHz}$. All the electrochemical measurements were conducted in $3 \mathrm{M} \mathrm{KOH}$ aqueous solution at $25 \pm 0.1^{\circ} \mathrm{C}$. Distilled water and analytical grade reagents were used to prepare the solutions.

The electrochemical tests for charge transfer and durability analyses were carried out on a CHI660D electrochemical workstation (CH Instruments, China) with a rotation disk electrode (Pine instrument), using a conventional three-electrode electrochemical cell at $25 \pm 0.1^{\circ} \mathrm{C}$. A glassy carbon electrode (GCE) with an area of $0.196 \mathrm{~cm}^{2}$ was used as the substrate for the working electrode, a ruthenium-titanium mesh and $\mathrm{Hg} / \mathrm{HgO}(1 \mathrm{M} \mathrm{KOH})$ were employed as the counter and reference electrodes, respectively. The catalyst ink was fabricated as follows: $2.67 \mathrm{mg}$ asprepared $\mathrm{Zr}^{4+}$ doped $\alpha-\mathrm{MnO}_{2}$ and $1.33 \mathrm{mg}$ acetylene black was ultrasonically dispersed in a $1.0 \mathrm{~mL}$ solution $(0.9 \mathrm{~mL}$ of ethanol and $0.1 \mathrm{~mL}$ of $5 \mathrm{wt} \%$ Nafion solution) for $30 \mathrm{~min}$. Then $10 \mu \mathrm{L}$ of the ink was pipetted onto the GCE surface, dried in air naturally. Linear sweep voltammetry (LSV) curves were obtained in $\mathrm{O}_{2}$ saturated $0.1 \mathrm{M} \mathrm{KOH}$ solution at different electrode rotated speeds with a potential scan rate of $5 \mathrm{mV} \mathrm{s}^{-1}$. The current-time durability measurement at $-0.4 \mathrm{~V}(v s . \mathrm{Hg} / \mathrm{HgO})$ was conducted by a rotating disk electrode (RDE) in $\mathrm{O}_{2}$-saturated $0.1 \mathrm{M} \mathrm{KOH}$ solution with a rotation rate of $1600 \mathrm{rpm}$. Koutecky-Levich plots (K-L plots) was fitted by a line and the slopes was used to analyse the number of electrons transferred $(n)$ during the ORR on the basis of Koutecky-Levich equation (K-L equation) $)^{45}$

$$
\begin{gathered}
\frac{1}{J}=\frac{1}{J_{\mathrm{k}}}+\frac{1}{B \omega^{-1 / 2}} \\
B=0.2 n F D^{2 / 3} v^{-1 / 6} C_{\mathrm{O}_{2}}
\end{gathered}
$$

where $J$ is the measured current density, $J_{\mathrm{k}}$ the kinetic current density, $B$ the Levich constant, $\omega$ the angular velocity of the rotating electrode, $F$ the Faraday constant $\left(96485 \mathrm{C} \mathrm{mol}^{-1}\right), D$ the diffusion coefficient of oxygen $\left(1.9 \times 10^{-5} \mathrm{~cm}^{-2} \mathrm{~s}^{-1}\right), v$ the kinetic viscosity of the electrolyte $\left(0.01 \mathrm{~cm}^{-2} \mathrm{~s}^{-1}\right), C_{\mathrm{O}_{2}}$ the bulk concentration of oxygen in electrolyte $\left(1.2 \times 10^{-6} \mathrm{~mol} \mathrm{~cm}^{-3}\right)$, and $n$ the number of electron exchanged during ORR process. The constant is adopted to be 0.2 when $\omega$ is expressed in rpm. ${ }^{46}$

\subsection{Density functional theory(DFT) calculations}

CASTEP $^{47,48}$ based on the Density Functional Theory (DFT) was used to investigate the $\mathrm{O}$ adsorption of $\alpha-\mathrm{MnO}_{2}$ and $\mathrm{Zr}^{4+}$ doped 
$\alpha-\mathrm{MnO}_{2}$ by solving the Kohn-Sham equation of a many-body system with an iterative approach. The system was under the periodic boundary condition and computation was done in a reciprocal space. Plane-wave basis sets with a cutoff energy of $340 \mathrm{eV}$. The General Gradient Approximation (GGA) ${ }^{49}$ of Perdew, Burke and Ernzerhof (PBE) ${ }^{50-52}$ was used as the exchangecorrelational functional to describe the interactions among electrons. The Brillouin zone integration was done on a grid of 3 $\times 2 \times 1$ with a Gaussian smearing parameter $\delta$ of $0.1 \mathrm{eV}$ and a Self-Consistence-Field (SCF) convergence criterion of $1 \times$ $10^{-5} \mathrm{eV}^{53}$ Initial structures were optimized by allowing the atoms positions to be relaxed while the iterative algorithm was updated by the conjugate gradient approach with convergence criteria of $0.05 \mathrm{eV} \AA^{-1}$. The crystal plane (211) of $\alpha-\mathrm{MnO}_{2}$ surface was modeled using three-layer periodic slabs repeating in a $(2 \times$ 2) surface structure. Periodic boundary conditions were applied in all three dimensions with a vacuum region of $12 \AA$ along the $z$-axis. The atoms in the top two layers of the slab were relaxed, whereas the atoms in the third layer were frozen at their bulk positions. Oxygen was placed on one side of the slab. Excluding these species and the top layer of the slab that were allowed to relax in their positions to reach the most stable configuration, all other atoms were frozen at their ideal bulk positions to simulate the bulk and reduce the computational cost.

The adsorption energies $\left(\Delta E_{\mathrm{ads}}\right)$ were defined relative to the isolated substrate and the molecules in the gas phase, as shown in eqn (3). A negative $\Delta E_{\text {ads }}$ value indicates favorable (exothermic) adsorption.

$$
\Delta E_{\text {ads }}=E_{(\text {adsorbate/catalyst })}-E_{\text {catalyst }}-E_{\text {adsorbate }}
$$

\section{Results and discussions}

\subsection{Characterization}

Fig. 1 shows the XRD patterns of the synthesized $\alpha-\mathrm{MnO}_{2}$ and $\mathrm{Zr}^{4+}$ doped $\alpha-\mathrm{MnO}_{2}$ catalysts with different $\mathrm{Zr} / \mathrm{Mn}$ molar ratios. It can be seen from Fig. 1a that all the patterns can be indexed to body-centered tetragonal $\alpha-\mathrm{MnO}_{2}$ (JCPDS NO. 44-0141, space group $I 4 / m, a=b=9.784 \AA, c=2.863 \AA$ ), indicating that the crystal structures of the synthesized catalysts are the same with $\alpha-\mathrm{MnO}_{2}$. It can also be observed from Fig. $1 \mathrm{~b}$ that the positions of the two characteristic peaks at $2 \theta=28.9$ and 37.6
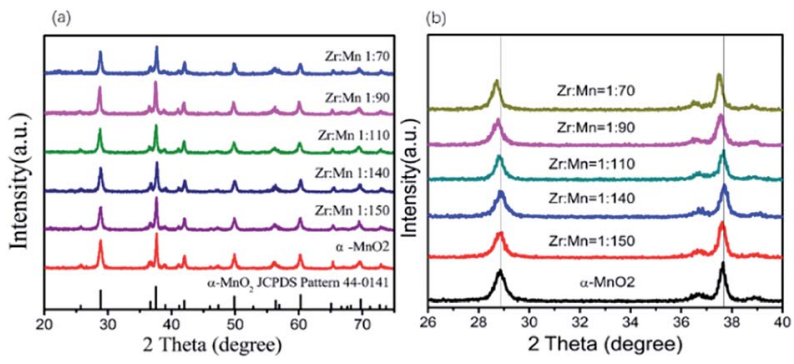

Fig. 1 XRD patterns of $\mathrm{Zr}^{4+}$ doped $\alpha-\mathrm{MnO}_{2}$ with different $\mathrm{Zr} / \mathrm{Mn}$ molar ratios. corresponding to crystal planes (310) and (211) remain the same as that of $\alpha-\mathrm{MnO}_{2}$ when the $\mathrm{Zr} / \mathrm{Mn}$ molar ratios in the catalysts are $1: 140$ and $1: 150$. With increasing $\mathrm{Zr} / \mathrm{Mn}$ molar ratio, a shift in the positions of the two characteristic peaks in Fig. $1 \mathrm{~b}$ appears at $\mathrm{Zr} / \mathrm{Mn}$ molar ratio $1: 110$ and the shift gets bigger at $\mathrm{Zr} / \mathrm{Mn}$ molar ratio $1: 90$ and $1: 70$. The shift in the peak positions means that a lattice distortion exists. The lattice parameters were calculated by the data in Fig. 1 and shown in Table 1. The lattice parameters $a, b$ and $c$ of $\mathrm{Zr}^{4+}$ doped $\alpha-\mathrm{MnO}_{2}$ become smaller compared with that of $\alpha-\mathrm{MnO}_{2}$. The changes in the lattice parameters also show a distortion in the lattice cell. The results above indicate that $\alpha-\mathrm{MnO}_{2}$ is successfully synthesized and element zirconium is doped into the lattice structure of $\alpha$ $\mathrm{MnO}_{2}$.

Fig. 2 shows the FE-SEM morphologies of $\alpha-\mathrm{MnO}_{2}$ and $\mathrm{Zr}^{4+}$ doped $\alpha-\mathrm{MnO}_{2}$ synthesized in this work. The two kinds of synthesized products all possess a wire shape with diameter less than $100 \mathrm{~nm}$. It can also be found that the surface of $\alpha-\mathrm{MnO}_{2}$ nanowires (Fig. 2a) is smoother than that of $\mathrm{Zr}^{4+}$ doped $\alpha-\mathrm{MnO}_{2}$ nanowires (Fig. 2b).

The high resolution TEM images of synthesized $\alpha-\mathrm{MnO}_{2}$ and $\mathrm{Zr}^{4+}$ doped $\alpha-\mathrm{MnO}_{2}$ nanowires ( $\mathrm{Zr} / \mathrm{Mn}$ molar ratio of $1: 110$ ) are shown in Fig. 3. The nanowires are straight in Fig. 3a and c, indicating that the crystal growth is along a preferred orientation. The diameter of synthesized $\alpha-\mathrm{MnO}_{2}$ nanowires is in the range of 10 to $50 \mathrm{~nm}$ and that of synthesized $\mathrm{Zr}^{4+}$ doped $\alpha-\mathrm{MnO}_{2}$ nanowires is in the range of 30 to $80 \mathrm{~nm}$. The surfaces of $\alpha$ $\mathrm{MnO}_{2}$ nanowires are clean and smooth (Fig. 3a and b). As for $\mathrm{Zr}^{4+}$ doped $\alpha-\mathrm{MnO}_{2}$ nanowires, some attachments exist on the nanowires (Fig. 3c and d). The attachments possess an irregular morphology and its crystal structure is different from the nanowires. The different crystal structure between the attachments and nanowires illustrates that the attachments and nanowires are different materials. A semi-coherent interfacial relationship can also been found between the nanowires and the attachments as shown in Fig. $3 \mathrm{~d}$ by the arrow, demonstrating that the attachments grow from the surface of the nanowires. The results above reveal that $\mathrm{Zr}^{4+}$ doped $\alpha-\mathrm{MnO}_{2}$ nanowires have been successfully synthesized and few attachments differing from $\alpha-\mathrm{MnO}_{2}$ in structure are formed at high $\mathrm{Zr}$ / Mn molar ratios.

XPS was used to probe the composition and chemical state of the synthesized nanowires, and the results are shown in Fig. 4. Compared with $\alpha-\mathrm{MnO}_{2}$ nanowires, a signal related to element zirconium is detected in $\mathrm{Zr}^{4+}$ doped $\alpha-\mathrm{MnO}_{2}$ nanowires as

Table 1 Lattice parameters calculated by the data in Fig. 1

\begin{tabular}{llll}
\hline & \multicolumn{2}{l}{ Lattice parameter } & \\
\cline { 2 - 4 } Sample & $a(\AA)$ & $b(\AA)$ & $c(\AA)$ \\
\hline$\alpha-\mathrm{MnO}_{2}$ & 9.815 & 9.815 & 2.847 \\
$\mathrm{Zr} / \mathrm{Mn} 1: 150$ & 9.7998 & 9.7998 & 2.845 \\
$\mathrm{Zr} / \mathrm{Mn} 1: 140$ & 9.7976 & 9.7976 & 2.842 \\
$\mathrm{Zr} / \mathrm{Mn} 1: 110$ & 9.7969 & 9.7969 & 2.845 \\
$\mathrm{Zr} / \mathrm{Mn} 1: 90$ & 9.7960 & 9.7960 & 2.844 \\
$\mathrm{Zr} / \mathrm{Mn} 1: 70$ & 9.7952 & 9.7952 & 2.845
\end{tabular}



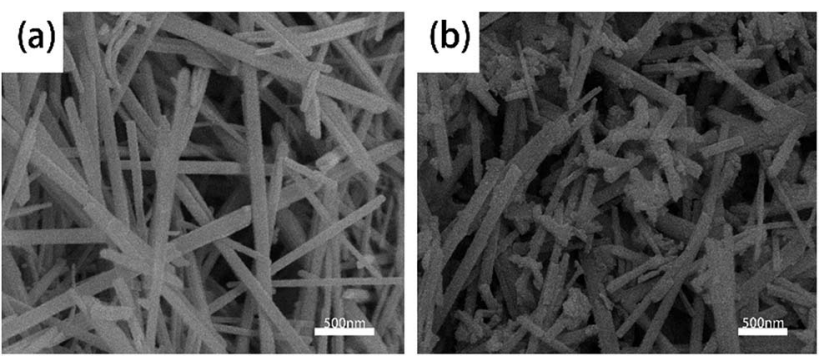

Fig. 2 FE-SEM images of (a) $\alpha-\mathrm{MnO}_{2}$ nanowires and (b) $\mathrm{Zr}^{4+}$ doped $\alpha$ $\mathrm{MnO}_{2}$ nanowires with $\mathrm{Zr} / \mathrm{Mn}$ molar ratio of $1: 110$.
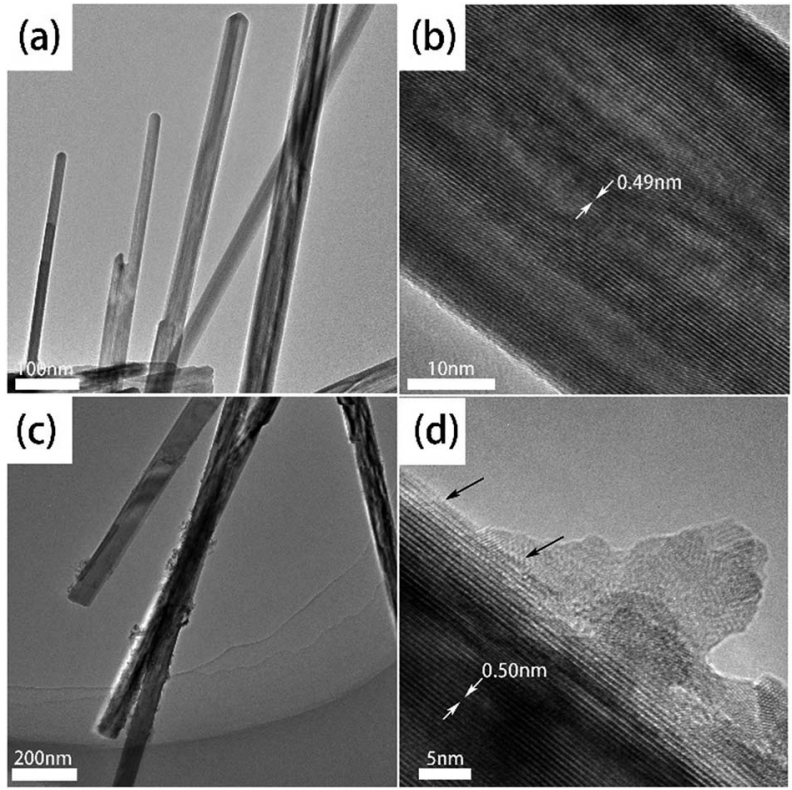

Fig. 3 TEM images of $\alpha-\mathrm{MnO}_{2}$ nanowires ( $\mathrm{a}$ and $\mathrm{b}$ ) and $\mathrm{Zr}^{4+}$ doped $\alpha$ $\mathrm{MnO}_{2}$ nanowires ( $c$ and $d$ ) with $\mathrm{Zr} / \mathrm{Mn}$ molar ratio of $1: 110$.

shown in Fig. 4a. Fig. 4b is the XPS spectrums of $\mathrm{O} 1 \mathrm{~s}$ for $\alpha$ $\mathrm{MnO}_{2}$ nanowires and $\mathrm{Zr}^{4+}$ doped $\alpha-\mathrm{MnO}_{2}$ nanowires. Curve simulations were conducted and the simulated curves are also shown in Fig. 4b. The fitted curve is in accord with the measured data, demonstrating the simulated results are reasonable. The binding energy values at the peak positions $529.4 \mathrm{eV}$ and $531.7 \mathrm{eV}$ in the $\mathrm{O} 1 \mathrm{~s}$ spectrum of $\alpha-\mathrm{MnO}_{2}$ nanowires correspond to the lattice oxygen and the adsorbed oxygen, respectively. ${ }^{54,55}$ It can also be seen from Fig. $4 \mathrm{~b}$ that the peak position corresponding to lattice oxygen shifts to $529.2 \mathrm{eV}$ while the peak position corresponding to adsorbed oxygen keeps the same after $\mathrm{Zr}^{4+}$ doping, which means that the chemical state of lattice oxygen in $\mathrm{Zr}^{4+}$ doped $\alpha-\mathrm{MnO}_{2}$ nanowires is altered compared with that in $\alpha-\mathrm{MnO}_{2}$ nanowires.

In order to obtain the detail information about the presence of element manganese, the XPS spectra of Mn $2 \mathrm{p}$ for $\alpha-\mathrm{MnO}_{2}$ nanowires were simulated with three groups of curves colored by pink, dark yellow and dark blue, respectively (Fig. 4c). The fitted curve is in accord with the measured data, demonstrating the simulated results are reasonable. The three groups of curves
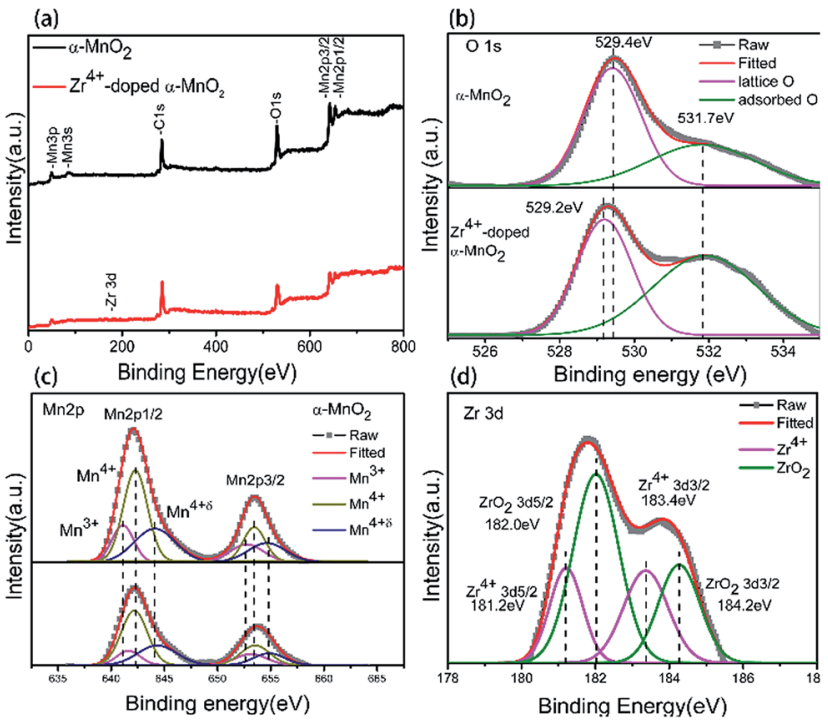

Fig. 4 XPS spectrums of $\alpha-\mathrm{MnO}_{2}$ and $\mathrm{Zr}^{4+}$ doped $\alpha-\mathrm{MnO}_{2}$ with $\mathrm{Zr} / \mathrm{Mn}$ molar ratio of 1 : 110. (a) Full spectrums; (b) O 1s; (c) Mn 2p; (d) $\mathrm{Zr} 3 \mathrm{~d}$.

correspond well to the XPS spectra of $\mathrm{Mn}^{3+}$ (pink), $\mathrm{Mn}^{4+}$ (dark yellow) and $\mathrm{Mn}^{4+\delta}$ (dark blue) in $\alpha-\mathrm{MnO}_{2},{ }^{56,57}$ indicating that there are three kinds of element manganese with different valences in $\alpha-\mathrm{MnO}_{2}$ nanowires. Comparing the XPS spectra of $\alpha$ $\mathrm{MnO}_{2}$ nanowires and $\mathrm{Zr}^{4+}$ doped $\alpha-\mathrm{MnO}_{2}$ nanowires in Fig. $4 \mathrm{c}$, it can be found that the peak position corresponding to $\mathrm{Mn}^{3+}$ shifts positively with $0.5 \mathrm{eV}$ while the peak position corresponding to $\mathrm{Mn}^{4+}$ and $\mathrm{Mn}^{4+\delta}$ remains the same after $\mathrm{Zr}^{4+}$ doping. The positive shift of $\mathrm{Mn}^{3+}$ binding energies with a value less than $1 \mathrm{eV}$ means that the chemical state of $\mathrm{Mn}^{3+}$ ions in $\mathrm{Zr}^{4+}$ doped $\alpha-\mathrm{MnO}_{2}$ has been changed and $\mathrm{Mn}^{3+}$ ions tend to lose their electrons by $\mathrm{Zr}^{4+}$ doping.

Fig. $4 \mathrm{~d}$ is $\mathrm{Zr3d}$ XPS spectrum of $\mathrm{Zr}^{4+}$ doped $\alpha-\mathrm{MnO}_{2}$ nanowires. The measured data were simulated with two group curves colored with pink and green. The fitted curve is consistent with the measured data, demonstrating the simulated results are reasonable. The binding energy values of green peaks in Fig. 4d are separately $182.0 \mathrm{eV}$ and $184.2 \mathrm{eV}$, which is in consistent with that of $\mathrm{ZrO}_{2} .^{58}$ The result manifests the existence of $\mathrm{ZrO}_{2}$. The binding energy values of pink peaks in Fig. $4 \mathrm{~d}$ are separately $181.2 \mathrm{eV}(\mathrm{Zr} 3 \mathrm{~d} 5 / 2)$ and $183.4 \mathrm{eV}(\mathrm{Zr} 3 \mathrm{~d} 3 / 2)$, which are $0.8 \mathrm{eV}$ negative shifts compared with that of green peaks in Fig. $4 \mathrm{~d}$. The negative shift in $\mathrm{Zr3d}$ binding energies with a value less than $1 \mathrm{eV}$ means that some zirconium ions in $\mathrm{Zr}^{4+}$ doped $\alpha-$ $\mathrm{MnO}_{2}$ tend to get electrons. Comprehensively considering the XPS results in Fig. 4, it can be concluded that $\mathrm{Mn}^{3+}$ ions, $\mathrm{Mn}^{4+}$ ions, $\mathrm{Mn}^{4+\delta}$ ions and $\mathrm{Zr}^{4+}$ ions co-existed in the crystal structure of synthesized $\mathrm{Zr}^{4+}$ doped $\alpha-\mathrm{MnO}_{2}$ nanowires. $\mathrm{Zr}^{4+}$ ions occupied the positions originally belonging to element manganese in the crystal structure and resulted in a mutual action between $\mathrm{Zr}^{4+}$ ions and $\mathrm{Mn}^{3+}$ ions. The mutual action made $\mathrm{Mn}^{3+}$ ions tend to lose their electrons and $\mathrm{Zr}^{4+}$ ions tend to get electrons. The existence of $\mathrm{Zr}^{4+}$ ions in the crystal structure also changed the chemical state of the lattice oxygen. XPS analyses in Fig. $4 \mathrm{~d}$ also indicate that there are some $\mathrm{ZrO}_{2}$ in $\mathrm{Zr}^{4+}$ doped $\alpha-\mathrm{MnO}_{2}$, 
which can be considered to be the attachments shown in Fig. 3d.

\subsection{Electrochemical activity of synthesized catalysts of ORR}

The cathodic polarization curves of the air electrodes prepared by $\alpha-\mathrm{MnO}_{2}$ nanowires and $\mathrm{Zr}^{4+}$ doped $\alpha-\mathrm{MnO}_{2}$ nanowires with different $\mathrm{Zr} / \mathrm{Mn}$ molar ratios were measured and the results are shown in Fig. 5a. As the potential moves negatively, the current density of the electrodes increases slowly in the potential range from $0.3 \mathrm{~V}$ to $0.1 \mathrm{~V}$. Then the current density begins to rise rapidly with the potential shifting more negative than $0.1 \mathrm{~V}$. According to the linear sweep voltammetry curves in Fig. 5a, the onset potentials of the electrodes were plotted in Fig. 5b. The onset potential of the electrodes prepared by pure $\alpha-\mathrm{MnO}_{2}$ is $0.02 \mathrm{~V}(v s . \mathrm{Hg} / \mathrm{HgO})$ while that of the electrodes prepared by $\mathrm{Zr}^{4+}$ doped $\alpha-\mathrm{MnO}_{2}$ catalyst with molar ratio $\mathrm{Zr}: \mathrm{Mn}=1: 90$ shows the highest onset potential $(0.082 \mathrm{~V})$. It can be observed that the onset potential increases with the rise of $\mathrm{Zr}: \mathrm{Mn}$ ratio and drops after reaching the peak value. To clearly show the effect of $\mathrm{Zr}$ / Mn molar ratios in the catalysts on the current density, the current densities at potential $-0.2 \mathrm{~V}$ in Fig. $5 \mathrm{a}$ were plotted against $\mathrm{Zr} / \mathrm{Mn}$ molar ratios and the curve is shown in Fig. 5c. The current density in Fig. $5 c$ alters in a volcano shape with $\mathrm{Zr}$ / Mn molar ratio increasing. The largest current density $(60 \mathrm{~mA}$ $\mathrm{cm}^{-2}$ ) emerges at $\mathrm{Zr} / \mathrm{Mn}$ molar ratio of $1: 110$, which is $23 \%$ larger than that of the electrode prepared with $\alpha-\mathrm{MnO}_{2}$ nanowires $\left(49 \mathrm{~mA} \mathrm{~cm}^{-2}\right)$. The current during the cathodic polarization process is caused by ORR on the surface of the electrodes. The larger the current density during the cathodic polarization process is, the more efficiently the catalyst promotes ORR. The results indicate that the electrocatalytic activity of $\alpha-\mathrm{MnO}_{2}$ on ORR can be remarkably improved by $\mathrm{Zr}^{4+}$ doping. After $\mathrm{Zr} / \mathrm{Mn}$ molar ratios exceeding 1:110, excessive zirconium forms $\mathrm{ZrO}_{2}$ crystals attached on the surfaces of $\mathrm{Zr}^{4+}$ doped $\alpha-\mathrm{MnO}_{2}$ nanowires as shown in Fig. 3d (the attachments). The existence of $\mathrm{ZrO}_{2}$ attachments reduces the catalytical area of $\mathrm{Zr}^{4+}$ doped $\alpha$ $\mathrm{MnO}_{2}$ nanowires, resulting in the decrease of the current density as shown in Fig. $5 \mathrm{~b}$.

The electrochemical impedance spectroscopies (EIS) of the air electrodes prepared by $\alpha-\mathrm{MnO}_{2}$ nanowires and $\mathrm{Zr}^{4+}$ doped $\alpha$ $\mathrm{MnO}_{2}$ nanowires with different $\mathrm{Zr} / \mathrm{Mn}$ molar ratios as catalysts were measured and shown in Fig. 6. All the EIS plots in Fig. 6a

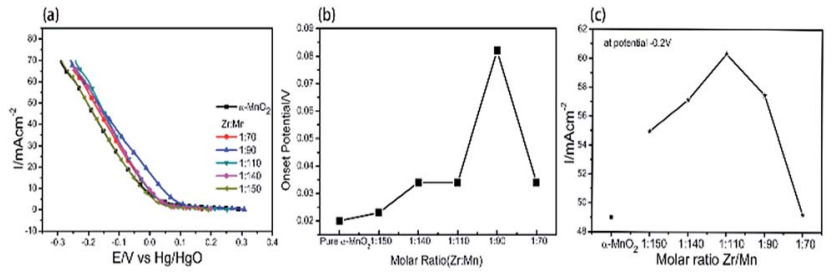

Fig. 5 (a) Cathodic polarization curves of the air electrodes prepared with $\alpha-\mathrm{MnO}_{2}$ nanowires and $\mathrm{Zr}^{4+}$ doped $\alpha-\mathrm{MnO}_{2}$ nanowires with different $\mathrm{Zr} / \mathrm{Mn}$ molar ratios as catalysts. (b) The onset potentials of the electrodes prepared by $\mathrm{Zr}^{4+}$ doped $\alpha-\mathrm{MnO}_{2}$ catalyst with different $\mathrm{Zr} /$ $\mathrm{Mn}$ ratios (c) the relations between $\mathrm{Zr} / \mathrm{Mn}$ molar ratios and the current densities at potential $-0.2 \mathrm{~V}$.
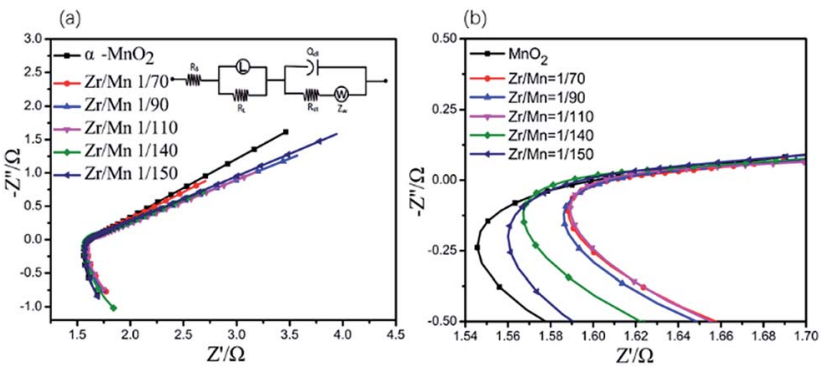

Fig. 6 (a) EIS of the air electrodes prepared by $\alpha-\mathrm{MnO}_{2}$ nanowires and $\mathrm{Zr}^{4+}$ doped $\alpha-\mathrm{MnO}_{2}$ nanowires with different $\mathrm{Zr} / \mathrm{Mn}$ molar ratios as catalysts. Upper inset is the equivalent circuit. (b) The amplified part of the EIS. Dot: measured data; solid line: simulated results.

exhibit the same shape, which are composed of a large arc in the high frequency range in the fourth quadrant linked with a very small semi-circle in the middle frequency range in the first quadrant followed by a long straight line in the low frequency range in the first quadrant.

The reduction of oxygen molecules on the surface of the air electrodes can be considered to proceed by following two steps. ${ }^{59}$ In the first step, oxygen molecules from the air diffuse through the air electrode and absorb on the surface of the air electrode near the solution side, which can be described in eqn (4). In the second step, absorbed oxygen molecules are electrochemically reduced and forms $\mathrm{OH}^{-}$, which can be described in eqn (5).

$$
\begin{gathered}
\mathrm{O}_{2} \rightarrow \mathrm{O}_{2} \text { adsorbed } \\
\mathrm{O}_{2} \text { adsorbed }+4 \mathrm{e}^{-}+2 \mathrm{H}_{2} \mathrm{O} \rightarrow 4 \mathrm{OH}^{-}
\end{gathered}
$$

The very small semi-circle in the EIS (Fig. 6) means that the electrochemical reduction of absorbed oxygen molecules described in eqn (5) is easy to proceed. The large arc in the EIS (Fig. 6) indicates that the adsorption of oxygen molecules described in eqn (4) is difficult to proceed. This suggests that the adsorption of oxygen molecules on the surface of the air electrodes is the rate-controlling step for ORR.

The EIS data were simulated using an equivalent circuit shown in Fig. 6b, and the simulated results are also shown in Fig. $6 \mathrm{a}$ in solid lines. Therein, $R_{\mathrm{s}}$ represents the solution resistance, $R_{\text {ct }}$ the charge transfer resistance incurred during the electrochemical reactions taking place on the electrodes, $Q$ the constant phase element modeling the non-faradaic processes, $Z_{\mathrm{W}}$ the Warburg element representing the diffusion control process, $L$ the inductance element representing the adsorption of oxygen molecules on the electrode, $R_{\mathrm{L}}$ the adsorption resistance. The solid lines in Fig. 6a fit well with the measured data, demonstrating the proposed equivalent circuit are reasonable. Some of the parameters in the equivalent circuit are listed in Table 2. It is well known that the reaction rate of the electrochemical reaction step is inversely proportional to $R_{\mathrm{ct}}{ }^{60}$ All the values of $R_{\mathrm{ct}}$ in Table 2 are small, illustrating that the reaction described in eqn (5) is easy to proceed. The electrode prepared with $\mathrm{Zr}^{4+}$ doped $\alpha-\mathrm{MnO}_{2}$ nanowires with $\mathrm{Zr} / \mathrm{Mn}$ molar ratio of 1 : 110 shows the smallest 
Table 2 Equivalent circuit elements and their values

\begin{tabular}{llllll}
\hline Sample & $L(\mathrm{H})$ & $R_{\mathrm{L}}(\Omega)$ & $R_{\mathrm{S}}(\Omega)$ & $Z_{\mathrm{W}}(\Omega)$ & $R_{\mathrm{ct}}(\Omega)$ \\
\hline$\alpha-\mathrm{MnO}_{2}$ & 1.422 & 4.685 & 1.804 & 1.57 & 29.81 \\
$1: 70$ & 1.367 & 3.221 & 1.565 & 1.84 & 27.34 \\
$1: 90$ & 1.336 & 3.195 & 1.524 & 2.68 & 24.42 \\
$1: 110$ & 1.391 & 3.141 & 1.308 & 2.46 & 20.64 \\
$1: 140$ & 1.886 & 3.721 & 1.679 & 1.67 & 29.34 \\
$1: 150$ & 1.53 & 4.849 & 1.9745 & 1.34 & 37.88 \\
& & & & &
\end{tabular}

value of $R_{\mathrm{L}}$. The smaller $R_{\mathrm{L}}$ value is, the more easily the adsorption process described in eqn (4) proceeds. Considering the adsorption of oxygen molecules is the rate-controlling step of ORR on the air electrode, the lowest $R_{\mathrm{L}}$ value reasonably explains why the catalyst with $\mathrm{Zr} / \mathrm{Mn}$ molar ratio $1: 110$ exhibits the highest electrocatalytical activity as shown in Fig. 6 .

To further elucidate the pathway and kinetics of ORR, LSV curve of the electrode prepared by $\mathrm{Zr}^{4+}$ doped $\alpha-\mathrm{MnO}_{2}$ on RDE were recorded at different rotation rates $(400-1600 \mathrm{rpm})$ in $\mathrm{O}_{2}-$ saturated $0.1 \mathrm{M} \mathrm{KOH}$ solution and the result is shown in Fig. 7a. The derived $\mathrm{K}-\mathrm{L}$ plot of $J^{-1}$ vs. $\omega^{-1 / 2}$ at a potential of $-0.4 \mathrm{~V}$ is shown in Fig. 7b. It can be found that a good linear relationship between $J^{-1}$ vs. $\omega^{-1 / 2}$. The electron transfer number $n$ was calculated by eqn (2) based on the slope $(1 / B)$ of the K-L plot. The electron transfer number for $\mathrm{Zr}^{4+}$ doped $\alpha-\mathrm{MnO}_{2}$ is 3.8, which clearly indicate that the electrode prepared by $\mathrm{Zr}^{4+}$ doped $\alpha-\mathrm{MnO}_{2}$ follows a desirable four-electron pathway for ORR.

The stability of catalysts is very important issue for their practical application in various energy technologies. Stability was examined during the ORR process. The durability of the electrode prepared by $\mathrm{Zr}^{4+}$ doped $\alpha-\mathrm{MnO}_{2}$ and $\mathrm{Pt} / \mathrm{C}$ as the catalyst for ORR was evaluated by chronoamperometric technique at potential $-0.4 \mathrm{~V}$ for $7200 \mathrm{~s}$. It can be seen from Fig. $7 \mathrm{c}$ that the ORR current density of the $\mathrm{Zr}^{4+}$ doped $\alpha-\mathrm{MnO}_{2}$ electrode decreased by only $16.3 \%$, but the Pt/C electrode exhibited a $30.1 \%$ decrease in current density under the same conditions. The result reveals that the performance of $\mathrm{Zr}^{4+}$ doped $\alpha-\mathrm{MnO}_{2}$ catalyst is more stable than that of the commercial Pt/C catalyst.

\subsection{Optimized configuration and $\mathrm{O}_{2}$ adsorption}

To understand the influence of $\mathrm{Zr}^{4+}$ doping on the adsorption of oxygen molecules, the DFT calculations were carried out aiming
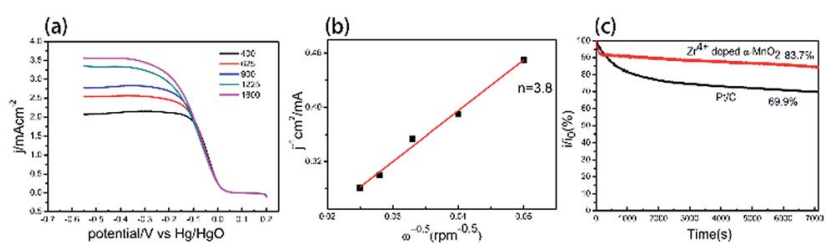

Fig. 7 (a) LSV curves of the electrodes prepared by $\mathrm{Zr}^{4+}$ doped $\alpha$ $\mathrm{MnO}_{2}$ catalyst at different rotation speed (400-1600 rpm) in oxygensaturated $0.1 \mathrm{M} \mathrm{KOH}$ solution. (b) Koutecky-Levich (K-L) plots. (c) Chronoamperometric curves of the electrode prepared by $\mathrm{Zr}^{4+}$ doped $\alpha-\mathrm{MnO}_{2}$ and $\mathrm{Pt} / \mathrm{C}$ measured in oxygen-saturated $0.1 \mathrm{M} \mathrm{KOH}$ solution at a rotating rate $1600 \mathrm{rpm}$.
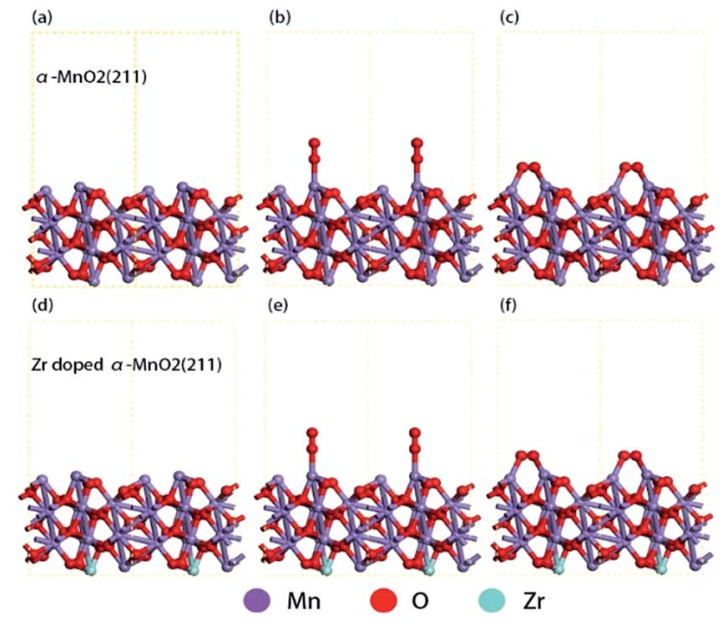

Fig. 8 Optimized adsorption structures. (a) Side view of the optimized $\alpha-\mathrm{MnO}_{2}$ (211) surface; (b) $\mathrm{O}_{2}$ top adsorption on $\alpha-\mathrm{MnO}_{2}$ (211) surface; (c) $\mathrm{O}_{2}$ bridge adsorption on $\alpha-\mathrm{MnO}_{2}$ (211) surface; (d) side view of the optimized $\mathrm{Zr}^{4+}$ doped $\alpha-\mathrm{MnO}_{2}$ (211) surface; (e) $\mathrm{O}_{2}$ top adsorption on $\mathrm{Zr}^{4+}$ doped $\alpha-\mathrm{MnO}_{2}$ (211); (f) $\mathrm{O}_{2}$ bridge adsorption on $\mathrm{Zr}^{4+}$ doped $\alpha-$ $\mathrm{MnO}_{2}$.

at the surface of crystal plane (211) of $\alpha-\mathrm{MnO}_{2}$ (Fig. 8a and d). Different adsorption configurations of $\mathrm{O}_{2}$ molecules were optimized by the computation methods mentioned in 2.4. The optimized adsorption structures on the surfaces are shown in Fig. 8b, c, e and f. The direct adsorption of $\mathrm{O}_{2}$ molecules on the surfaces includes the following two modes: top adsorption (Fig. $7 \mathrm{~b}$ and e) and bridge adsorption (Fig. $7 \mathrm{c}$ and f). The adsorption energy of $\mathrm{O}_{2}$ molecules was calculated by eqn (3) and the results were listed in Table 3.

As shown in Table 3, the bridge adsorption energy is more negative than top adsorption energy, indicating that bridge adsorption is more favorable for $\mathrm{O}_{2}$ molecules. Comparing with $\alpha-\mathrm{MnO}_{2}$, the bridge absorption energy of $\mathrm{O}_{2}$ molecules on $\mathrm{Zr}^{4+}$ doped $\alpha-\mathrm{MnO}_{2}$ decreases by $0.26 \mathrm{eV}$. The more negative adsorption energy indicates an easier adsorption process and a more stable adsorption structure. ${ }^{61,62}$ The results in Table 3 reveal that the mutual action between $\mathrm{Zr}^{4+}$ and $\mathrm{Mn}^{3+}$ in $\mathrm{Zr}^{4+}$ doped $\alpha-\mathrm{MnO}_{2}$ nanowires enhances the adsorption process of $\mathrm{O}_{2}$ molecules. The bridge adsorption configuration is supposed to be the preferential adsorbing manner for $\mathrm{O}_{2}$ molecules on the surface of $\mathrm{Zr}^{4+}$ doped $\alpha-\mathrm{MnO}_{2}$. According to EIS analyses, the adsorption process of $\mathrm{O}_{2}$ molecules is the rate-controlling step for ORR. The results in Table 3 provide a reasonable explanation about the improvement in the performance of ORR by $\mathrm{Zr}^{4+}$ doping.

Table 3 Adsorption energy of $\mathrm{O}_{2}$ molecules with different configurations

\begin{tabular}{lll}
\hline Surface & Top adsorption/eV & Bridge adsorption/eV \\
\hline $\begin{array}{l}\text { Crystal plane (211) } \\
\text { of } \alpha-\mathrm{MnO}_{2}\end{array}$ & -1.2242 & -2.8777 \\
$\begin{array}{l}\text { Crystal plane (211) } \\
\text { of } \mathrm{Zr} \text { doped } \alpha-\mathrm{MnO}_{2}\end{array}$ & -1.3313 & -3.1317
\end{tabular}

of $\mathrm{Zr}$ doped $\alpha-\mathrm{MnO}_{2}$ 


\section{Conclusions}

$\mathrm{Zr}^{4+}$ doped $\alpha-\mathrm{MnO}_{2}$ nanowires were successfully synthesized by a hydrothermal method. XRD, SEM, TEM and XPS analyses indicated that $\mathrm{Mn}^{3+}$ ions, $\mathrm{Mn}^{4+}$ ions, $\mathrm{Mn}^{4+\delta}$ ions and $\mathrm{Zr}^{4+}$ ions co-existed in the crystal structure of synthesized $\mathrm{Zr}^{4+}$ doped $\alpha$ $\mathrm{MnO}_{2}$ nanowires. $\mathrm{Zr}^{4+}$ ions occupied the positions originally belonging to element manganese in the crystal structure and resulted in a mutual action between $\mathrm{Zr}^{4+}$ ions and $\mathrm{Mn}^{3+}$ ions. The mutual action made $\mathrm{Mn}^{3+}$ ions tend to lose their electrons and $\mathrm{Zr}^{4+}$ ions tend to get electrons. The existence of $\mathrm{Zr}^{4+}$ ions in the crystal structure also changed the chemical state of the lattice oxygen. Cathodic polarization analyses showed that $\mathrm{Zr}$ / Mn molar ratio notably affects the ORR performance of the air electrodes prepared by $\mathrm{Zr}^{4+}$ doped $\alpha-\mathrm{MnO}_{2}$ nanowires. The highest ORR current density of the air electrodes prepared by $\mathrm{Zr}^{4+}$ doped $\alpha-\mathrm{MnO}_{2}$ nanowires in alkaline solution appeared at $\mathrm{Zr} / \mathrm{Mn}$ molar ratio of $1: 110$, which was $23 \%$ higher than that prepared by $\alpha-\mathrm{MnO}_{2}$ nanowires. The results indicated that the electrocatalytic activity of $\alpha-\mathrm{MnO}_{2}$ for ORR remarkably improved by $\mathrm{Zr}^{4+}$ doping. EIS analyses indicated that the adsorption process of $\mathrm{O}_{2}$ molecules on the surface of the air electrodes prepared by $\mathrm{Zr}^{4+}$ doped $\alpha-\mathrm{MnO}_{2}$ nanowires was the rate-controlling step for ORR. The calculation results based on density functional theory (DFT) revealed that the mutual action between $\mathrm{Zr}^{4+}$ and $\mathrm{Mn}^{3+}$ in $\mathrm{Zr}^{4+}$ doped $\alpha-\mathrm{MnO}_{2}$ nanowires enhanced the adsorption process of $\mathrm{O}_{2}$ molecules.

\section{Conflicts of interest}

There are no conflicts to declare.

\section{Acknowledgements}

This research is supported by the Chinese Natural Science Foundation (No. 21276181). We are grateful for the support.

\section{Notes and references}

1 X. Huang, Z. Zhao, L. Cao, Y. Chen, E. Zhu, Z. Lin, M. Li, A. Yan, A. Zettl, Y. M. Wang, X. Duan, T. Mueller and Y. Huang, Science, 2015, 348, 1230.

2 C. Chen, Y. Kang, Z. Huo, Z. Zhu, W. Huang, H. L. Xin, J. D. Snyder, D. Li, J. A. Herron, M. Mavrikakis, M. Chi, M. N. Markovic, G. A. Somorjai, P. Yang and V. R. Stamenkovic, Science, 2014, 343, 1339.

3 V. R. Stamenkovic, B. Fowler, B. S. Mun, G. F. Wang, P. N. Ross, C. A. Lucas and N. M. Markovic, Science, 2007, 315, 493-497.

4 V. Komanicky, H. Iddir, K. C. Chang, A. Menzel, G. Karapetrov, D. Hennessy, P. Zapol and H. You, J. Am. Chem. Soc., 2009, 131, 5732-5733.

5 C. L. Lee, C. M. Syu, H. P. Chiou, C. H. Chen and H. L. Yang, Int. J. Hydrogen Energy, 2011, 36, 10502-10512.

6 L. Tammeveski, H. Erikon, A. Sarapuu, J. Kozlova, P. Ritslaid, V. Sammelselg and K. Tammeveski, Electrochem. Commun., 2012, 20, 15-18.
7 B. P. Vinayan, K. Sethupathi and S. Ramapraabhu, Int. J. Hydrogen Energy, 2013, 38, 2240-2250.

8 G. F. Alvarez, M. Mamlouk and S. M. Senthil Kumar, J. Appl. Electrochem., 2011, 41, 925-937.

9 P. Fu, L. H. Zhou, L. H. Sun, B. H. Huang and Y. Yuan, RSC Adv., 2017, 7, 13383-13389.

10 Y. Z. Xu, C. L. Chen, M. Zhou, G. Y. Fu, Y. Y. Zhao and Y. H. Chen, RSC Adv., 2017, 7, 26722-26728.

11 W. X. Wang, Y. Shi, M. C. Li, Z. Y. Wang, S. F. Wu, F. C. Lyu, C. Q. Shang and Z. G. Lu, RSC Adv., 2016, 6, 110758-110764.

12 R. Bashyam and P. Zelenay, Nature, 2006, 443, 63-66.

13 X. Y. Xu, C. X. Shi, Q. Li, R. Chen and T. H. Chen, RSC Adv., 2017, 7, 14382-14388.

14 G. Panomsuwan, N. Saito and T. Ishizaki, RSC Adv., 2016, 6, 114553-114559.

15 X. W. Bai, E. J. Zhao, W. C. Wang, Y. Wang, K. Li, L. Lin, J. C. Yang, H. Sun and Z. J. Wu, RSC Adv., 2017, 7, 2381223819.

16 S. Jin, A. G. Hubert, Y. Naoaki, N. Haruyuki, B. G. John and S. H. Yang, Nat. Chem., 2011, 3, 546-550.

17 Y. Y. Liang, H. L. Wang, J. G. Zhou, Y. G. Li, J. Wang, T. Regier and H. J. Dai, J. Am. Chem. Soc., 2012, 134, 35173523.

18 J. Xu, P. Gao and T. S. Zhao, Energy Environ. Sci., 2012, 5, 5333-5339.

19 Z. S. Wu, S. Yang, Y. Sun, K. Parvea, X. L. Feng and K. Mullen, J. Am. Chem. Soc., 2012, 134, 9082-9085.

20 N. S. Lewis and D. G. Nocera, Proc. Natl. Acad. Sci. U. S. A., Early Ed., 2006, 103, 15729-15735.

21 A. J. Bard and M. A. Fox, Acc. Chem. Res., 1995, 28, 141-145.

22 I. Roche, E. Chainet and M. Chatenet, J. Phys. Chem. C, 2007, 111, 1434-1443.

23 M. L. Calegaro, F. H. B. Lima and E. A. Ticianelli, J. Power Sources, 2006, 158, 735-739.

24 Y. L. Cao, H. X. Yang, X. P. Ai and L. F. Xiao, J. Electroanal. Chem., 2003, 557, 127-134.

25 M. Lanqun, T. Sotomura, K. Nakatsu, N. Koshiba, Z. Dun and T. Ohsaka, J. Electrochem. Soc., 2002, 149, A504-A507.

26 F. H. B. Lima, M. L. Calegaro and E. A. Ticianelli, J. Electroanal. Chem., 2006, 590, 152-160.

27 S. Devaraj and N. Munichandraiah, J. Phys. Chem. C, 2008, 112, 4406-4417.

28 F. Cheng, Y. Su, J. Liang, Z. Tao and J. Chen, Chem. Mater., 2009, 22, 898-905.

29 Y. J. Zhang, C. S. Sun, P. Lu, K. Y. Li, S. Y. Song and D. F. Xue, CrystEngComm, 2012, 14, 5892-5897.

30 K. Selvakumar, S. M. S. Kumar, R. Thangamuthu, G. Kruthika and P. Murugan, Int. J. Hydrogen Energy, 2014, 39, 21024-21036.

31 F. Cheng, J. Shen, W. Ji, Z. Tao and J. Chen, ACS Appl. Mater. Interfaces, 2009, 1, 460-466.

32 W. Xiao, D. Wang and X. W. Lou, J. Phys. Chem. C, 2010, 114, 1694-1700.

33 L. Mao, D. Zhang, T. Sotomura, K. Nakatsu, N. Koshiba and T. Ohsaka, Electrochim. Acta, 2003, 48, 1015-1023.

34 F. Cheng, T. Zhang, Y. Zhang, J. Du, X. Han and J. Chen, Angew. Chem., Int. Ed., 2013, 52, 2474-2477. 
35 D. A. Slanac, A. Lie, J. A. Paulson, K. J. Stevenson and K. P. Johnston, J. Phys. Chem. C, 2012, 116, 11032-11039.

36 Q. Tang, L. Jiang, J. Qi, O. Jiang, S. Wang and G. Sun, Appl. Catal., B, 2011, 104, 337-345.

37 S. W. Liu and X. Qin, RSC Adv., 2015, 5, 15627-15633.

38 W. Sun, A. Hsu and R. Chen, J. Power Sources, 2011, 196, 4491-4498.

39 I. Roche, E. Chainet and M. Vondrak, J. Phys. Chem. C, 2007, 111, 1434-1443.

40 A. C. Garcia, A. D. Herrera, E. A. Ticianelli, M. Chatenet and C. Poinsignon, J. Electrochem. Soc., 2011, 158, B290-B296.

41 K. A. Walz, C. S. Johnson, J. Genthe, L. C. Stoiber, W. A. Zeltner, M. A. Anderson and M. M. Thackeray, $J$. Power Sources, 2010, 195, 4943-4951.

42 J. Xu, G. Chen, H. J. Zhang, W. Zheng and Y. Li, J. Appl. Electrochem., 2015, 45, 123-130.

43 V. Subramanian, H. W. Zhu and B. Q. Wei, J. Power Sources, 2006, 159, 361-364.

44 F. Hashemzadeh, M. M. K. Motlagh and A. Maghsoudipour, J. Sol-Gel Sci. Technol., 2009, 51, 169-174.

45 R. E. Davis, G. L. Horvath and C. W. Tobias, Electrochim. Acta, 1967, 12, 287.

46 K. Chen, Y. J. Hao and M. R. Zhang, RSC Adv., 2017, 7, 5782.

47 M. C. Payne, D. C. Allan, T. A. Arias and J. D. Joannopoulos, Rev. Mod. Phys., 1992, 64, 1045.

48 V. Milman, B. Winkler, J. A. White, C. J. Pickard, M. C. Payne, E. V. Akhmataskaya and R. H. Nobes, Int. J. Quantum Chem., 2000, 77, 895.

49 J. A. White and D. M. Bird, Phys. Rev. B, 1976, 13, 5188.
50 J. P. Perdrew, K. Burke and M. Ernzerhof, Phys. Rev. Lett., 1996, 77, 3865-3868.

51 J. P. Perdrew, K. Burk and M. Ernzerhof, Phys. Rev. Lett., 1997, 78, 1396.

52 Y. H. Li, G. Y. Zhong and F. Peng, Phys. Chem. Chem. Phys., 2015, 17, 21950.

53 H. J. Monkhorst and J. Pack, Phys. Rev. B, 1976, 13, 5188.

54 F. Wang, H. X. Dai, J. G. Deng, G. M. Bai, K. M. Ji and Y. X. Liu, Environ. Sci. Technol., 2012, 46, 4034-4041.

55 J. B. Jia, P. Y. Zhang and L. Chen, Appl. Catal., B, 2016, 189, 210-218.

56 D. A. Pena, B. S. Uphade and P. G. Smirniotis, J. Catal., 2004, 221, 421-431.

57 E. Pargoletti, G. Cappelletti, A. Minguzzi, S. Rondinini, M. Leoni, M. Marelli and A. Vertova, J. Power Sources, 2016, 325, 116-128.

58 C. D. Wagner, W. M. Riggs, L. E. Davis and J. F. Moulder, Handbook of X-Ray Photoelectron Spectroscopy, ed. G. E. Mullenberg, Perkin-Elmer Corporation Press, Minnesota, 1979, vol. 2, p. 100.

59 Z. Shi, J. J. Zhang, Z. S. Liu, H. J. Huang and D. P. Wikinson, Electrochim. Acta, 2006, 51, 1905-1916.

60 Z. He and F. Mansfeld, Energy Environ. Sci., 2009, 2, 215-219.

61 L. Li, Z. D. Wei, S. G. Chen, X. Q. Qi, W. Ding, M. R. Xia, R. Li, K. Xiong, Z. H. Deng and Y. Y. Gao, Chem. Phys. Lett., 2012, 539, 88-93.

62 M. H. Yu, Z. K. Wang and C. Hou, Adv. Mater., 2017, 29, 1602868. 